\title{
Association of Normal Breathing Rate with Mouth Shape
}

\author{
Muhammad Imran Qadir and Muhammad Kashan Javed* \\ Institute of Molecular Biology and Biotechnology, Baha Uddin Zakariya University, Multan, Pakistan \\ *Corresponding Author: Muhammad Kashan Javed, Institute of Molecular Biology and Biotechnology, Baha Uddin Zakariya University, \\ Multan, Pakistan.
}

Received: July 01, 2019; Published: July 17, 2019

DOI: $10.31080 /$ ASMI.2019.02.0314

\begin{abstract}
The objective of present survey was to find any association between the breathing and the shape of mouth Almost 200 persons were participated in the current survey For the measurement of breathing rate, every person who contributed in the current survey, count their breathing rate for one minute and mention their breathing rate on the questionnaire which we provided them. A questionnaire was set to find any interaction between the breathing and the shape of mouth. We found from the present survey that the normal breathing rate had scientific interaction with mouth shape because the value of $p$ is lower than 0.1 that's why the result considered as significant
\end{abstract}

Keywords: Association; Breathing; Mouth

\section{Introduction}

Breathing referred to the process of taking air in and out of the lungs in order to serve the exchange of gases with the inner environment. In this process an individual take oxygen in to the lungs and expel carbon di oxide out of the lungs to complete the process of breathing. It is an repetitive phenomena of life and is very essential for the life. If you are feeling stress then do breathing exercise for the relief and for calmness. Every segment of human body unable to survive without oxygen brain, heart, lungs etc. each and every part of human body need oxygen for the survival.

The topic of my discussion is relation of breathing with the shape of mouth so first of all we take some idea about the shape of mouth. There are many forms of mouth shape like pearl in the sea shaped mouth, they have certain features like they are extremely dangerous and play tricks behind. Lined shaped mouth ,the person with lined shaped mouth have poor relations with people and are prone to dangerous things. Blow fire mouth, the person with blow fire mouth have bad luck for their family. Round shaped mouth, the person with round shaped mouth have poor communication with the opposite sex and they remain self-willed.
The objective of present survey was to find any association between the breathing and the shape of mouth.

\section{Material and Method}

- Almost 200 persons were participated in the current survey

- $\quad$ For the measurement of breathing rate, every person who contributed in the current survey, count their breathing rate for one minute and mention their breathing rate on the questionnaire which we provided them.

- A questionnaire was set to check any association between the breathing rate and the mouth shape

\section{Statistical analysis}

Statistical examination was done with the help of t-Test and SAS (Statistical Analysis Software).

\section{Result and Discussion}

Association between the normal breathing rate with the shape of mouth is listed in Table 1 . Table 1 clarify that there is scientific association between the normal breathing rate with the shape of 
mouth because the value of $p$ is less than 0.1 that's why the result considered as significant.

\begin{tabular}{|l|c|c|c|}
\hline Gender & $\begin{array}{c}\text { Round shape } \\
\text { mouth }\end{array}$ & $\begin{array}{c}\text { Oval shape } \\
\text { mouth }\end{array}$ & p-VALUE \\
\hline Male & $23.93 \pm 5.11$ & $19.85 \pm 2.60$ & $0.01^{*}$ \\
\hline Female & $19.86 \pm 4.12$ & $20.82 \pm 6.87$ & 0.43 \\
\hline Combined & $21.91 \pm 2.89$ & $20.35 \pm 0.68$ & 0.31 \\
\hline
\end{tabular}

Table 1: Regular Breathing Rate In Respect with The Shape of Mouth (Mean \pm SD).

$\left({ }^{*} p<0.1\right.$ hence $p$ considered as significant)

An investigation was set in order to check any association between the normal breathing rate and the mouth shape [1-7].

\section{Conclusion}

We found from the present survey that the normal breathing rate had scientific interaction with mouth shape because the value of $p$ is lower than 0.1 that's why the result considered as significant.

\section{Bibliography}

1. Reith J., et al. "Body temperature in acute stroke: relation to stroke severity, infarct size, mortality, and outcome". The Lancet 347 (1996): 422-425.

2. Refinetti R and Menaker M. "The circadian rhythm of body temperature". Physiology and behaviour 51 (1992): 613-637.

3. Qadir MI and Saleem A. "Awareness about ischemic heart disease in university biotechnology students". Global Advanced Research Journals 7.3 (2018): 059-061.

4. Qadir MI and Ishfaq S. "Awareness about hypertension in biology students". International Journal of Pharmaceutical Research 7 (2018): 08-10.

5. Qadir MI and Mehwish. "Awareness about psoriasis disease". International Journal of Pharmaceutical Research 7 (2018): 17-18.

6. Qadir MI and Shahzad R. "Awareness about obesity in postgraduate students of biotechnology". International Journal of Pharmaceutical Research 7 (2018): 14-16.
7. Qadir MI and Rizvi M. "Awareness about thalassemia in post graduate students". MOJ Lymphology and Phlebology 2 (2018): 14-16.

8. Qadir MI and Ghalia BA. "Awareness survey about colorectal cancer in students of M. Phil Biotechnology at Bahauddin Zakariya University, Multan, Pakistan". NACS 1 (2018).

Volume 2 Issue 8 August 2019

(C) All rights are reserved by Muhammad Imran Qadir and Muhammad Kashan Javed. 